\title{
A Classification Approach for Predicting COVID-19 Patient's Survival Outcome with Machine Learning Techniques
}

\author{
Abdulhameed Ado Osi ${ }^{1 * \pi}$, Mannir Abdu ${ }^{1 \S}$, Usman Muhammad ${ }^{3 \S}$, Auwalu Ibrahim ${ }^{1 \S}$, Lawan Adamu \\ Isma' $^{11}{ }^{1 \S}$, Ahmad Abubakar Suleiman ${ }^{1 \S}$, Hasssan Sarki Abdulkadir ${ }^{1 \S}$ Safiya Sani Sada ${ }^{4 \S}$, Hussaini Garba \\ Dikko $^{2 \S}$ and Muftahu Zubairu Ringim ${ }^{2}$
}

${ }^{1}$ Department of Statistics, Kano University of Science and Technology, Wudil, Nigeria.

${ }^{2}$ Department of Mathematics, Kano University of Science and Technology, Wudil, Nigeria.

${ }^{3}$ Department of Statistics, Ahmadu Bello University, Zaria, Nigeria

${ }^{4}$ Department. of Agronomy, Ahmadu Bello University, Zaria, Nigeria.

aaosi@kustwudil.edu.ng +2348069120811

* Corresponding author

abuammarosi@gmail.com; aaosi@kustwudil.edu.ng (AAO) +2348069120811

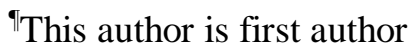

${ }^{\S}$ These authors contributed equally to this work 


\begin{abstract}
COVID-19 is an infectious disease discovered after the outbreak began in Wuhan, China, in December 2019. COVID-19 is still becoming an increasing global threat to public health. The virus has been escalated to many countries across the globe. This paper analyzed and compared the performance of three different supervised machine learning techniques; Linear Discriminant Analysis (LDA), Random Forest (RF), and Support Vector Machine (SVM) on COVID-19 dataset. The best level of accuracy between these three algorithms was determined by comparison of some metrics for assessing predictive performance such as accuracy, sensitivity, specificity, F-score, Kappa index, and ROC. From the analysis results, RF was found to be the best algorithm with $100 \%$ prediction accuracy in comparison with LDA and SVM with $95.2 \%$ and $90.9 \%$ respectively. Our analysis shows that out of these three classification models RF predicts COVID-19 patient's survival outcome with the highest accuracy. Chi-square test reveals that all the seven features except sex were significantly correlated with the COVID-19 patient's outcome (P-value < 0.005). Therefore, RF was recommended for COVID-19 patient's outcome prediction that will help in early identification of possible sensitive cases for quick provision of quality health care, support and supervision.
\end{abstract}

Key Words: COVID-19, Survival outcomes, Random Forest, Linear Discriminant Analysis, Support Vector Machine

\title{
1. Introduction
}

In December, 2019 an outbreak of pneumonia of unknown cause emerged in Wuhan, Hubei Province, China that led to the discovery of coronavirus. Since then, the disease has been spreading rapidly to more than 150 countries across the globe with more than 3,132,000 confirmed cases of infection and about 230,000 deaths as at $30^{\text {th }}$ April,2020 [1]. In February 2020 the World health organization termed this newly discovered disease as COVID-19 (coronavirus 2019) and subsequently declared it as pandemic on $12^{\text {th }}$ March, 2020 [2]. COVID-19 also known as Severe Acute Respiratory Syndrome Coronavirus 2 (SARS-CoV-2) is a communicable disease that cause respiratory infection that is generally similar to Severe Acute Respiratory Syndrome (SARS-CoV) and Middle East Respiratory Syndrome (MERS-CoV) in severe cases. The disease can be transmitted from person to person via a droplets coming out from the mouth or nose of infected person. The most common symptoms of COVID-19 are: fever; fatigue and dry cough [3]. Some patients may have sore throat, diarrhea, headache and nasal congestion. However, most COVID-19 patients don't develop any symptoms (asymptotic). 
medRxiv preprint doi: https://doi.org/10.1101/2020.08.02.20129767; this version posted August 10, 2020. The copyright holder for this preprint (which was not certified by peer review) is the author/funder, who has granted medRxiv a license to display the preprint in perpetuity.

It is made available under a CC-BY 4.0 International license .

Current studies have shown that most of the COVID-19 patients with underline comorbidity and elderly patients are more likely to develop severe cases which may require ICU care and could lead to death [4]. Several existing literature reported diabetes and hypertension as the most common comorbidities for people with COVID-19 [3] [5] [4] [6]. Although, clinical results showed that being diabetic or hypertensive has no association with the risk of contracting the diseases [7]. However, it could increase chances for severe and critical COVID-19 conditions [8] [3].

Currently, the ongoing pandemic (COVID-19) has attracted the interest of many researchers. Different statistical models have been used in many studies to predict COVID-19 cases, prevalence and mortality [9] used Multivariate Logistic Regression to determine the risk factor associated with mortality, [3] used Cox Regression Models to explore potential risk factors associated with clinical outcomes, While [10] applied Chi-square Test and Spearman's Ranked Correlation to explored the significant differences between severe and non-severe COVID-19 cases using the clinical and laboratory characteristic of hospitalized patients. [11] used the Mann Whitney U test or Kruskal-Wallis test for comparison significance differences for univariate and chi-square for categorical variables, and then modeled patient's survival with Hierarchical Cox Regression to identify poor outcome risk population. [12] applied Chisquare to test the association between being HFABP positive and COVID-19 severity using epidemiological, clinical, and laboratory characteristics.

Machine Learning is modern data analysis technique deals with patterns and correlations to extract useful information from the raw data. Machine Learning played a significant role in fighting the previous epidemic, more especially in the area of the disease diagnosis, medication, prediction and drug/vaccine development [13]. Numerous Machine Learning Algorithms have shown powerful prediction capabilities in the diseases prediction [14] [15] [16] [17]. Machine learning technique has recently gained attention for the COVID-19 outbreak spreading prediction [18].. There is gap in the literature for studies dedicated to COVID-19, most of the existing studies are limited to cases prediction. This study focuses on the application of supervised machine learning techniques (i.e SM, RF, LDA) to predict the survival outcome 
medRxiv preprint doi: https://doi.org/10.1101/2020.08.02.20129767; this version posted August 10, 2020. The copyright holder for this preprint (which was not certified by peer review) is the author/funder, who has granted medRxiv a license to display the preprint in perpetuity.

It is made available under a CC-BY 4.0 International license .

of COVID-19 patients based on some demographic, clinical and epidemiological characteristics. Also to assess the performance of the methods using seven different metrics. The paper equally investigates the effect of these demographics and clinical variables to the patient's outcome.

\section{Material and Methods}

\subsection{Dataset and variables}

This study uses detail information of patients' demographic, epidemiological, clinical characteristics (including age, sex, comorbidities, hospital length of stay, travel history, signs, and symptoms), and their definite survival outcomes (discharge or death) available at https://drive.google.com/file/d/1bYcMAd-1OiSlOVG15qxG1Sq1auyzmWHZ/view . A total sample of 425 confirmed of COVID-19 patients were extracted and who were died or discharged on or before $11^{\text {th }}$ March, 2020 were included in the study. This study was approved by the General Research Ethics Committee of the Kano University of Science and Technology, Wudil, Nigeria. The data were partitioned into two parts (training and test data set), the first part (80\%) was used to develop the learning algorithms while the second part (20\%) to test the performances of the algorithms.

\subsection{Prediction models}

Three different types of classification models: Linear Discriminant Analysis (LDA), Random Forest (RF), and Support Vector Machines (SVM) were used. These methods have been widely reported and demonstrated as successful methods for classification [17]. Description of each of these classification models is given below.

\subsubsection{Linear Discriminant Analysis}

Discriminant Analysis (DA) find a set of prediction equation based on independent variables that are used to classify individuals. The main objectives of DA are to find a predictive equation for classifying new individuals and interpreting the predictive equation for a better understanding of the relationship among the variables. 
Linear Discriminant Analysis (LDA) formulated by [19] is most commonly used DA. The original Linear Discriminant Analysis was described for a 2-class problem,, and it was later generalized to multiple class by [20]. LDA makes some assumptions about the dataset: the data is Gaussian, and each attribute has the same variance.

LDA use of Bayes theorem to construct the decision rule. Let $\pi_{k}$ represent the prior probability of $\mathrm{k}^{\text {th }}$ class, and let $f_{k}(X) \equiv \operatorname{Pr}(X=x \mid Y=k)$ denote a conditional density of $\mathrm{X}$ given that the observation comes from $\mathrm{k}^{\text {th }}$ class. The posterior probability is given as

$$
P(Y=k \mid X=x)=\frac{\pi_{k} f_{k}(X)}{\sum_{l=1}^{K} \pi_{l} f_{l}(X)}
$$

By the two LDA assumptions

$$
f_{k}(X)=\frac{1}{(2 \pi)^{1 / 2}\left|\Sigma_{k}\right|^{1 / 2}} e^{-1 / 2(x-\mu)^{T} \Sigma_{k}^{-1}(x-\mu)}
$$

Where $\Sigma_{k}=\Sigma \forall_{k}$

The decision rule is to assign an observation $\mathrm{X}=\mathrm{x}$ to the class for which

$$
\delta_{k}(x)=x^{T} \Sigma^{-1} \mu_{k}-\frac{1}{2} \mu_{k}^{T} \Sigma^{-1} \mu_{k}+\log \left(\pi_{k}\right) \text { is largest. }
$$

\subsubsection{Support Vector Machine.}

The Support Vector Machine (SVM) is a powerful technique for general (nonlinear supervised machine learning algorithm that is suitable for linear and non-linear problems and can be used for both regression and classification. The aim of SVM is to find a hyperplane in a multidimensional space that splits the feature space into two distinct groups. A new subject is then classified based on which side of the hyperplane he lies on. SVM uses kernel function to converts non-separable problems into separable problems by mapping the training data into higher-dimensional feature space, then finds the hyperplane that maximizes the distance from the nearest subjects and achieves maximum separation. The kernel function can be linear, polynomial or radial, and the choice of the kernel can have a large effect on model 
medRxiv preprint doi: https://doi.org/10.1101/2020.08.02.20129767; this version posted August 10, 2020. The copyright holder for this preprint (which was not certified by peer review) is the author/funder, who has granted medRxiv a license to display the preprint in perpetuity.

It is made available under a CC-BY 4.0 International license .

outputs. SVM method has successfully achieved high predictive performance in health care researches. In this study, we implemented SVM using the "e1071" package in the R statistical environment.

\subsubsection{Random forest.}

Random Forests (RF) developed by [21] are among the most widely used machine learning algorithm. In RF a "forest" of decision trees are generated on different bootstrap samples by re-sampling the training data that limit. for each single decision tree a random subset of features is randomly chosen at each node to decide optimal split. For classification problems, the ensemble of simple trees votes for the most popular class. The response of each tree depends on a set of predictor values chosen independently (with replacement) and with the same distribution for all trees in the forest, which is a subset of the predictor values of the original data set. The Random Forest has two important parameters, the number of predictive variables to randomly choose at each node for splitting (mtry) and the number of trees to grow in the forest (ntree) [21]. In this study we used the R package "randomForest", with 1000 trees and mtry $=3$, which is square root of the total number of predictor variables.

\subsection{Performance evaluation for the classification methods}

Model performance evaluation is a core part of constructing effective machine learning model. The evaluation can be performed with a set of performance measure metrics, most of whom are derived from confusion matrix. The confusion matrix compares the original (observed) class with predicted class. It consists of four possible outcomes; TP stands for true positives TN (true negatives), FP (false positives), and FN (false negatives). TP and TN are representing a situation whereby the classifier correctly classified positive and negative ("Died" and "Discharged" in our case) instances respectively. FP denotes number of cases where the model misclassified positive as negative while FN represents patients negative incorrectly classified as positive. Table 1 shows layout of the confusion matrix.

\section{Table1: Confusion matrix}

\begin{tabular}{|l|l|}
\hline & Predicted \\
\hline
\end{tabular}




\begin{tabular}{|l|l|l|}
\hline Observed & P & N \\
\hline P & TP & FN \\
\hline N & FP & TN \\
\hline
\end{tabular}

Generally, there is no universally accepted metric for measuring classifiers performance. However, the choice of metric depends on the application. Care need to be taken on how choose the evaluation metrics as it is obvious that, at the same time a classifier could perform very well on a particular metric and badly on the another. Therefore, correct selection of performance metrics is essential to achieve reliable results. [22] suggested that, a classifier should be evaluated using set of performance metrics that ate not closely related to reduce redundancy. In this study, we employed seven most commonly evaluation metrics of two different types; threshold metric (precision, accuracy, sensitivity, specificity, F-score and kappa) and rank metric(AUC-ROC). The metrics are defined below.

i. Accuracy: Accuracy is a widely used metric for monitoring machine learning models performance and defines as the ration of the correctly classified instances to total number of instances, for unbalanced data this metric can be misleading.

$$
\text { Accuracy }=\frac{T P+T N}{T N+F P+F N+T P}
$$

ii. F-score: The F-score is a single-value metric based on two parameters. It is weighted average of the precision and recall values. In other word, is the harmonic mean of the precision and recall. The range of F-score is between 0 and 1 (1 means perfect).

$$
F-\text { score }=\frac{2 * \text { Recall } * \text { Precision }}{\text { Recall }+ \text { Precision }}=\frac{2 . T P}{2 . T P+F P+F N}
$$

iii. Kappa: Kappa is a coefficient developed to measure observed agreement normalized to the agreement by chance. 


$$
K=\frac{P_{\text {obs }}-P_{\text {chance }}}{1-P_{\text {chance }}}
$$

iv. Sensitivity/Recall: Sensitivity is defined as the proportion of positive instances that are correctly classified as positive, with respect to all positive set.

$$
\text { Sensitivity } / \text { Recall }=\frac{T P}{T P+F N}
$$

v. Specificity: Specificity is the proportion negative instances that are correctly identified as negative out of the total observed negative instances

$$
\text { Specificity }=\frac{T N}{T N+F P}
$$

vi. Precision: Precision is the true positive divided by the sum of all positive prediction

$$
\text { Precision }=\frac{T P}{T P+F P}
$$

vii. $\quad \boldsymbol{R} \boldsymbol{O C}-\boldsymbol{A} \boldsymbol{U C}$ : An ROC stands for Receiver Operating Characteristics is graphical plot illustrate binary classifier performance for various thresholds. ROC is created by plotting the true positive rate (TPR) against the false positive rate (FPR) at various threshold settings [23]. The area under the ROC curve (AUC) summarized the ROC performance to single value, it ranged between 0 and 1. A higher AUC value represents the superiority of a classifier and vice versa [14]

\section{Results}

The mean age of the patients was 53.1 years old (the median was 54) and majority (61.2\%) of

\begin{tabular}{|c|c|c|c|c|c|}
\hline \multicolumn{2}{|c|}{ Demographics and clinical Variables } & \multirow{2}{*}{$\begin{array}{l}\text { Total } \\
14(3.3 \%)\end{array}$} & \multirow{2}{*}{$\begin{array}{l}\text { Died }(\mathrm{n}=163) \\
0\end{array}$} & \multirow{2}{*}{$\begin{array}{l}\text { Discharged }(\mathbf{n}=\mathbf{2 6 2}) \\
14(3.3)\end{array}$} & \multirow{2}{*}{$\begin{array}{l}\text { P-value } \\
0.000\end{array}$} \\
\hline \multirow{5}{*}{ Age group } & $0-19$ years & & & & \\
\hline & 20-39 years & $121(28.5)$ & $3(0.7)$ & $118(27.8)$ & \\
\hline & $40-59$ years & $117(27.5)$ & $27(6.4)$ & $90(21.2)$ & \\
\hline & $60-79$ & $121(28.5)$ & $83(19.6)$ & $28(8.9)$ & \\
\hline & $80+$ years & $52(12.2)$ & $50(11.8)$ & $2(0.5)$ & \\
\hline
\end{tabular}
them were male Overall, 38.4\% (163) of patients were died and 61.6\% (262) discharged alive.

Table 2: Distribution of demographic and clinical characteristics of COVID-19 patients with the survival outcome 
medRxiv preprint doi: https://doi.org/10.1101/2020.08.02.20129767; this version posted August 10, 2020. The copyright holder for this preprint (which was not certified by peer review) is the author/funder, who has granted medRxiv a license to display the preprint in perpetuity.

It is made available under a CC-BY 4.0 International license.

\begin{tabular}{|c|c|c|c|c|c|}
\hline \multirow[t]{2}{*}{ Sex } & Female & $165(38.5)$ & $60(36.4)$ & $105(63.6)$ & \multirow[t]{2}{*}{0.502} \\
\hline & Male & $260(61.2)$ & 103 (39.6) & $157(60.4)$ & \\
\hline \multirow[t]{14}{*}{ Symptoms } & arrhythmia & $1(1.2)$ & $1(100)$ & 0 & \multirow[t]{14}{*}{0.000} \\
\hline & acute respiratory distress & $50(11.8)$ & $50(100)$ & 0 & \\
\hline & arrhythmia & $4(0.9)$ & $4(100)$ & 0 & \\
\hline & cough \& fever & $28(6.6)$ & $6(21.4)$ & $22(78.6)$ & \\
\hline & diarrhea & $2(0.5)$ & 0 & $2(100)$ & \\
\hline & difficulty breathing & $2(0.5)$ & $2(100)$ & 0 & \\
\hline & discomfort & $2(0.5)$ & 0 & $2(100)$ & \\
\hline & dry cough & $1(0.2)$ & $1(100)$ & 0 & \\
\hline & fever \& fatigue & $27(6.4)$ & $9(33.3)$ & $18(66.7)$ & \\
\hline & myelofibrosis & $1(0.2)$ & $1(100)$ & 0 & \\
\hline & pneumonia & $25(5.9)$ & $25(100)$ & 0 & \\
\hline & respiratory symptoms & $2(0.5)$ & 0 & $2(100)$ & \\
\hline & sore throat & $2(0.5)$ & $1(50)$ & $1(50)$ & \\
\hline & NONE & $278(63.4)$ & $63(22.7)$ & $215(77.3)$ & \\
\hline \multirow[t]{2}{*}{ Travel history } & $\mathrm{NO}$ & $333(78.4)$ & $157(47.1)$ & $176(52.9)$ & \multirow[t]{2}{*}{0.000} \\
\hline & YES & $92(21.6)$ & $6(6.5)$ & $86(96.5)$ & \\
\hline \multirow{2}{*}{$\begin{array}{l}\text { Comorbidity } \\
\text { (binary) }\end{array}$} & $\mathrm{NO}$ & $317(74.5)$ & $75(23.7)$ & $242(76.3)$ & \multirow[t]{2}{*}{0.000} \\
\hline & YES & $108(25.4)$ & $88(81.5)$ & $20(18.5)$ & \\
\hline \multirow[t]{11}{*}{ Comorbidity } & $\overline{\text { Asthma }}$ & $5(1.2)$ & $2(40)$ & $3(60)$ & \multirow[t]{11}{*}{0.000} \\
\hline & cardiac disease & $1(0.2)$ & $1(100)$ & 0 & \\
\hline & chronic kidney disease & $7(1.6)$ & $7(100)$ & 0 & \\
\hline & COPD & $2(0.5)$ & 0 & $2(100)$ & \\
\hline & diabetes & $22(5.2)$ & $22(100)$ & 0 & \\
\hline & hepatitis B & $2(0.5)$ & $2(100)$ & 0 & \\
\hline & hypertension & $61(14.4)$ & $49(80.3)$ & $12(19.7)$ & \\
\hline & prostate cancer & $2(0.5)$ & $2(100)$ & 0 & \\
\hline & prostate hypertrophy & $2(0.5)$ & 0 & $2(100)$ & \\
\hline & pulmonary disease & $2(0.5)$ & $2(100)$ & 0 & \\
\hline & NONE & $319(75.1)$ & $76(23.8)$ & $243(76.2)$ & \\
\hline \multirow[t]{2}{*}{ LOS } & Above & $186(43.8)$ & $6(3.2)$ & $180(96.8)$ & \multirow[t]{2}{*}{0.000} \\
\hline & Below & $239(56.2)$ & $157(65.7)$ & $82(34.3)$ & \\
\hline
\end{tabular}

As shown in Table 2 above and visualized in Fig.1 below, 3.3\% (14) of the patients were less than 20 years of age and all of them survived the disease, $28.5 \%$ (121) aged between 20 to 39 and $27.8 \%$ (118) of them discharged alive, $27.5 \%$ (117) were between 40 to 59 years old of which $76.9 \%$ (90) of them discharged from hospital, $28.5 \%$ (121) of the patients were within 60 to 79 years of age and only $31,4 \%$ (38) of them survived, lastly $12.2 \%$ (52) of the patients aged 80 years and above of which $96.2 \%$ (50) of them died for COVID-19. The result for test of significant difference between age group and survival outcome, indicates p-value $=0.000(<0.05)$. Hence, the null hypothesis is rejected and conclude that the two variables (age and patients' survival outcome) relate to each other (dependent). As for distribution of the sex of the patients, $33.8 \%$ of the patients were female and $63.5 \%$ of them were discharged while $60.4 \%$ of the male survived. The chi-square test result for Sex and patient's outcome has P-value $=0.5690$ (> 0.05) which indicates the two variables are in fact independent. 
medRxiv preprint doi: https://doi.org/10.1101/2020.08.02.20129767; this version posted August 10, 2020. The copyright holder for this preprint (which was not certified by peer review) is the author/funder, who has granted medRxiv a license to display the preprint in perpetuity.

It is made available under a CC-BY 4.0 International license .

Symptoms of the patients on admission as shown in Table 2, 63.4\% (278/425) of the patient are asymptotic while 147 have shown at least one symptoms and the most commonly experienced symptoms were acute respiratory distress 34\%(50/147) followed by cough \& fever $19.1 \%$ (28/147), and fever \& fatigue $18.4 \%(27 / 147)$. On the relationship between onset symptoms and survival status, $77.3 \%$ (215) of patients reported no symptoms on admission survived the disease. All patients with acute respiratory symptoms died and more than $70 \%$ of patients with onset fever were discharged. A similar result was illustrated in Fig. 2. The associativity test between symptoms and survival outcome result has P-value $=$ $0.000(\mathrm{P}<0.05)$ hence, the two variables are statistically significantly related.

The distribution of travel history and survival status of COVID-!19 patients are as follows. 78.4\% of the patient has no travel history and $52,9 \%$ of them discharged. The mortality rate of a patient with travel history is $6.5 \%$. the chi-square result showed the emergence of a significant association between travel history and survival outcome with p-value $<0.05$.

The comorbidity was in this case treated as binary (YES versus NO) before subsequently, grouped based on specific comorbidity. [3] point out that both the dummy variable and specific comorbidity could be simultaneously used in predicting COVID-19 patients' survival outcome. Results from crosstabulation indicates $25.4 \%$ of the patients under study have a history of underline medical problems of whom only $18.5 \%$ of them survived and $81.5 \%$ were died which indicates very high mortality rate of patients with comorbidity. The associativity test of chi-square reveals dependency between Chronic diseases and survival outcome (P-value=0.000) and Fig.3 explains further the nature of associativity, as we can see having comorbidity (YES) is inversely associated with "Discharged" and positively correlated with "Death". This means those with comorbidity diseases are more likely to die with COVID-19 while those without it have a higher chance of recovering from the disease.

Table 2 also expressed the distribution of specific comorbidities recorded on admission. 106 (24.1\%) patients had at least one underlying comorbidity, the most frequent of which were chronic diseases, such as hypertension (57.5\%) and diabetes (20.6\%), only two COPD patients were identified. 
medRxiv preprint doi: https://doi.org/10.1101/2020.08.02.20129767; this version posted August 10, 2020. The copyright holder for this preprint (which was not certified by peer review) is the author/funder, who has granted medRxiv a license to display the preprint in perpetuity.

It is made available under a CC-BY 4.0 International license .

All patients with diabetes and kidney disease died on admission while more than $80 \%$ of the patients with hypertension died. Out of 425 patients, $75.1 \%$ (319) had no documented comorbidity and 76.2\% (243) of them were discharged alive. The Chi-square test results describe the specific comorbidities and survival outcome to have a statistical significant relationship

Hospital Length of Stay (LOS) was converted from numerical to dummy variable using the average length of stay (ALOS) which was calculated to be 9 days, all the patients stayed above average were tagged "A" and those stayed below average tagged "B". Table 2 shows the distribution of the stratified LOS and survival outcome, among 186 patients stayed above ALOS 180 (96.8\%) were discharged. Death was higher in patients stayed below ALOS, 157 (65.7) out of 239 of them died. The results can be visualized from Fig. 4 which indicated the longer patient stayed the more likely he is to survive the disease.

Fig 1: Distribution of age group and survival outcome

Fig 2: Distribution of symptoms and survival outcome

Fig. 3 Distribution of comorbidity (binary) and outcome

Fig. 4 Distribution of length of stay and survival outcome

\subsection{Linear Discriminant Analysis}

Confusion matrix was utilized to visualize the performance of the machine learning algorithms as on test data for which the true values are known after building the models using the training set. Confusion matrix outcome was used to calculate model performance evaluation metrics such as accuracy, precision and soon. 
Table

\begin{tabular}{|c|c|c|c|}
\hline \multirow[b]{2}{*}{$\begin{array}{l}\text { Predicted } \\
\text { classes }\end{array}$} & \multicolumn{2}{|c|}{ Observed classes } & \\
\hline & Died & Discharged & Row Total \\
\hline Died & 30 & 2 & 32 \\
\hline Discharged & 2 & 50 & 52 \\
\hline Column Total & 32 & 52 & 84 \\
\hline
\end{tabular}

represents

the confusion matrix for the LDA model, as it can be seen that the model was able to predict 30 dead patients correctly and misclassified 2 as discharged, also correctly classified 50 discharged patients and misclassified 2. The model has an overall classification accuracy of 0.95 (95\%).

\subsection{Random Forest}

Table 4: Confusion matrix for RF

\begin{tabular}{|c|c|c|c|}
\hline \multirow[b]{2}{*}{$\begin{array}{l}\text { Predicted } \\
\text { classes }\end{array}$} & \multicolumn{3}{|c|}{ Observed classes } \\
\hline & Died & Discharged & Row Total \\
\hline Died & 32 & 0 & 32 \\
\hline Discharged & 0 & 52 & 52 \\
\hline Column Total & 32 & 52 & 84 \\
\hline
\end{tabular}

Table 4. showed model performance for the random forest classifier using the confusion matrix.

The model appears to perform perfectly by correctly classifying all 32 dead patients and classified all 52 discharged patients correctly without any misclassification, leading to the overall classification accuracy of $100 \%$ and therefore the error rate is $0 \%$. The importance of each predictor in determining the survival outcome of CIVID-19 patients with a random forest model was also explored and the result was presented in Fig. 5, LOS is the most important variable followed by age then symptoms using both Mean Decrease Accuracy and Mean Decrease Gini. Sex is a less important variable.

Figure 5: plot for variable importance 


\subsection{Support Vector Machine}

Table 5: Confusion matrix for SVM

\begin{tabular}{|l|l|l|l|}
\hline \multirow{2}{*}{$\begin{array}{c}\text { Predicted } \\
\text { classes }\end{array}$} & \multicolumn{3}{|c|}{ Observed classes } \\
\cline { 2 - 5 } & Died & Discharged & Row Total \\
\hline Died & 30 & 3 & $\mathbf{3 3}$ \\
\hline Discharged & 2 & 49 & $\mathbf{5 1}$ \\
\hline Column Total & $\mathbf{3 2}$ & $\mathbf{5 2}$ & $\mathbf{8 4}$ \\
\hline
\end{tabular}

Let's have a look at the results of the performance of the SVM algorithm on the test dataset in

Table 5, in which 30 out of 32 died patients are correctly classified and 2 were misclassified while 49 out of 52 discharged patients were correctly classified. The overall classification accuracy was $94 \%$ and the apparent error rate of $6 \%$.

\subsection{Performance comparison of the models}

Table 6. Summary of model performance for the three classifiers

\begin{tabular}{l|c|l|c|c|c|c|c} 
Classifiers & Accuracy & Precision & Sensitivity & Specificity & F-score & Kappa & AUC \\
\hline LDA & 0.952 & 0.938 & 0.938 & 0.962 & 0.938 & 0.899 & 0.991 \\
\hline RF & 1.000 & 1.000 & 1.000 & 1.000 & 1.000 & 1.000 & 0.994 \\
\hline SVM & 0.941 & 0.938 & 0.909 & 0.961 & 0.923 & 0.875 & 0.970
\end{tabular}

We compared the classification accuracy of the three different supervised machine learning algorithms namely, LDA, RF, and SVM. All of the algorithms performed absolutely well by achieving greater than $90 \%$ accuracy. The recall and precision rates for each of the algorithms also showed a similar result to that seen with overall accuracy. Table 6 shows the predictive performances of the classifiers for the test data set. It is observed that RF have better performance on all evaluation metrics: accuracy (100\%), 
medRxiv preprint doi: https://doi.org/10.1101/2020.08.02.20129767; this version posted August 10, 2020. The copyright holder for this preprint (which was not certified by peer review) is the author/funder, who has granted medRxiv a license to display the preprint in perpetuity.

It is made available under a CC-BY 4.0 International license .

precision, recall, specificity, F-score, Kappa and AUC, followed by LDA which also performed very well, its prediction accuracy has been calculated as $95.2 \%$ of accuracy, $93.8 \%$ recall, $96.2 \%$ specificity, and 89.9\% Kappa index. Fig. 7 illustrates the ROC graph for the three classifiers (i.e., LDA, RF, and SVM). Figure 6 shows three ROC curves for all the three developed models based on the given outcome. RF has outperformed the other classifiers with an area under the curve(AUC) 0.994. Similarly, LDA and SVM perform excellently with the area under the curve(AUC) 0.991 and 0.970 respectively.

Figure 6: ROC curve for LDA, RF and SVM on the task of classifying survival outcome of COVID-19 patients

\section{Discussion}

This study explored factors influencing survival outcomes of COVID-19 patients. The mean age of all patients was 53.1 years (the median was 54) which is close to that of data reported by [4] [24] 56.0 years and [10] 57 years, older than 48.9 years reported by [3] and, but younger than that reported by [11]73 years and [6] 70.6 years. Chi-square test was used to test the associativity between the six predictors and survival outcome. Table 2 shows the results considering a significant level of 0.05 . Age was discovered to be highly associated with the survival outcome, it was found that those with older age had a higher likelihood to die of COVID-19 than those with younger age. the results also indicate independence between sex and survival outcome. Age has previously reported by many researchers including [24] [25] [11] to be associated with the death of patients with COVID-19. [25] reported sex not have significance in determining patient's outcome. Results of this analysis as displayed in Table 2 shows that $63.4 \%$ (278) of patients reported no symptoms on admission. The most frequent symptoms were acute respiratory distress, cough, fever and fatigue. [4] [5] [3] highlighted fever, fatigue and dry cough as the most common COVID-19 symptoms. It is further observed that patient with onset symptoms are more likely to die of the disease. Also patients with acute respiratory distress and pneumonia are most vulnerable to severe condition that could lead to death. The finding on patients with morbidity is that out of the 425 patients we studied $108(25.4 \%)$ have reported at least one morbidity on admission and only less than $20 \%$ of them discharged alive. Hypertension (57.5\%) and diabetes (20.6\%) were the most common underlying 
medRxiv preprint doi: https://doi.org/10.1101/2020.08.02.20129767; this version posted August 10, 2020. The copyright holder for this preprint (which was not certified by peer review) is the author/funder, who has granted medRxiv a license to display the preprint in perpetuity.

It is made available under a CC-BY 4.0 International license .

diseases and recorded higher mortality rates. These supported the [3] [5] [4] [6] findings. Hospital Length of Stay (LOS) was found to influence the patient's survival outcome, Table 2 shows that $96.8 \%$ of patients stayed longer than the average length of stay survived. Hence, longer LOS increases the chances of patients been discharged alive.

The study developed a machine learning techniques for prediction of COVID-19 patient's survival outcome after a hospital stay, using the patients' demographic and clinical characteristics believed to contributed to the outcomes. Three methods LDA, RF, and SVM were applied on the COVID-19 data set, our results were presented in Tables 3-5 using a confusion matrix which determines classifiers performance based on classified instances. According to Table 3 LDA correctly classified 80 instances out of 84 , yielding accuracy of $95.4 \%$. The performance of RF was presented in Table 4, this algorithm correctly classified all the instances with zero misclassification. Table 5 shows the performance of SVM algorithms which classified 79 instances correctly out of a total number of 84 instances having an accuracy of $90.9 \%$. From these we can conclude that based on accuracy RF classifier presented a higher performance in comparison with the others.

The general performances of the models were examined based on seven performance metrics. consider Table 6, it clearly shown that RF has highest accuracy (100\%), recall (100\%), precision (1.00) and specificity (1.00) when comparing with LDA who has Accuracy (0.952), recall (0.938), precision (0.938) and specificity (0.962) and SVM has Accuracy (0.941), recall (0.909), precision (0.983) and specificity (0.961), we can clearly see that RF is the best model while LDA is the better then SVM. Based on the Kappa Statistic which is used to assess the accuracy of any particular measuring cases, RF has the highest value of 1.00 followed by LDA (0.899) then SVM (0.875). ROC curve represents the combination of sensitivity and specificity. Theoretically, the area under the ROC (AUC) can assume values between 0 and 1 , where an ideal classifier will take the value of 1 . However, the practical lower bound for random classification is 0.5 which means the classifier with no discriminative capability. Whereas classifiers with an AUC significantly higher than 0.5 have at least some ability to discriminate. the experimental results 
medRxiv preprint doi: https://doi.org/10.1101/2020.08.02.20129767; this version posted August 10, 2020. The copyright holder for this preprint (which was not certified by peer review) is the author/funder, who has granted medRxiv a license to display the preprint in perpetuity.

It is made available under a CC-BY 4.0 International license .

of the study were displayed in Figure 4 for LDA, RF, and SVM. All the algorithms did well but the AUC for RF is 0.994 , showing the reliability of discriminative capability among all the methods. We can conclude that both LDA, RF and SVM perform outstandingly. However, the RF algorithm is considered the best supervised machine learning algorithms of this study.

\section{Conclusions}

This paper presents a comparative studies of three machine learning algorithms to predict of the survival outcomes of COVID-19 patients. The algorithms were evaluated on seven different performance metrics (accuracy, sensitivity, specificity, and precision, recall, F-measure, ROC and AUC). The results shown solid prediction capabilities of Machine Learning Techniques in prediction of COVID-19 patients survival status, all the algorithms performed very well but the RF classifier are considered as best model. The study also demonstrates that, patients with underline comorbidities and aging patient are more likely to develop severe situation, and have little chance of surviving COVID-19. In terms of duration of hospital stay the longer patient stays the higher chance of his surviving. Early detection COVID-19 patients is essential for identification of vulnerable patients who may need special care to survive the disease, optimal usage of resources as well as estimation of number of beds required in intensive care units.

\section{References}

[1] W. H. Organization, "World Health Organization," 30 April 2020. [Online]. Available: www.who,int.

[2] World Health Organization, ". Coronavirus Disease 2019 (COVID-19) Situation Report 68," World Health Organization, 2020.

[3] W.-j. Guan, W.-h. Liang, H.-r. Liang, Z.-s. Chen, Y.-m. Li, X.-q. Liu, R.-c. Chen, C.-I. Tang, T. Wang, C.-q. Ou, L. Li, . P.-y. Chen, L. Sang and W. Wang, "Comorbidity and its impact on 1590 patients with COVID-19 in China: a nationwide analysis," Eur Respir J, vol. 55, 2020. 
[4] D. Wang, , B. HU, C. Hu, F. Zhu, X. Liu, J. Zhang, B. Wang, X. Hui, Z. Cheng, Y. Xiong, Y. Zhao, Y. Li, $X$. Wang and Z. Peng, "Clinical Characteristics of 138 Hospitalized Patients With 2019 Novel Coronavirus-Infected Pneumonia in Wuhan, China," JAMA, vol. 323, no. 1, pp. 1061-1069, 2020.

[5] L. Orioli , M. P. Hermans, J.-P. Thissen, D. Maiter, B. Vandeleene and J.-C. Yombi, "COVID-19 in diabetic patients: Related risks and specifics of management," Annales d'Endocrinologie, vol. 80, pp. 101-109, 2020.

[6] C. Leung, "Clinical features of deaths in the novel coronavirus epidemic in China," Rev Med Virol, 2020.

[7] L. Fang, G. Karakiulakis and M. Roth, "Are patients with hypertension and diabetes mellitus at increased risk for COVID-19 infection?," Elsevier, 2020.

[8] H. Z. ,. Y. Z. ,. X. W. ,. Y. Z. ,. Y. L. ,. W. T. ,. M. Y. ,. X. D. ,. J. Z. ,. R. L. ,. H. L. ,. R. M. E. , Y. H. ,. H. N. ,. Y. W. Xiaofan Liu, "Risk Factors Associated with Disease Severity and Length of Hospital Stay in COVID-19 Patients," Journal of Infection, pp. 1-8, 2020.

[9] F. Zhou, T. Yu, . R. Du, G. Fan, Y. Liu, Z. Liu, J. Xiang, Y. Wang, B. Song, X. Gu, L. Guan, Y. Wei, H. Li, . X. Wu, J. Xu, S. Tu, Y. Zhang, H. Chen and B. Cao, "Clinical course and risk factors for mortality of adult inpatients with COVID-19 in Wuhan, China: a retrospective cohort study," Lancet, vol. 395, p. 1054-62, 2020.

[10] J.-j. Zhang, X. Dong, Y.-y. Cao, Y.-d. Yuan, Y.-b. Yang, Y.-q. Yan, C. A. Akdis and Y.-d. Gao, "Clinical characteristics of 140 patients infected with SARSCoV-2 in Wuhan, China," Allergy, p. 00:1-12, 2020.

[11] A. B. Docherty, E. M. Harrison, C. A. Green, H. E. Hardwick, R. Pius, L. Norman, K. A. Holden, J. M. Read, F. Dondelinger, G. Carson, L. Merson, J. Lee, D. Plotkin, L. Sigfrid, S. Halpin, C. Jackson, C. Gamble, P. W. Horby, J. S. Nguyen-Van-Tam, A. Ho, C. D. Russell, J. Dunning, P. J. Openshaw, . K. J. Baillie and M. G. Semple, "Features of 20133 UK patients in hospital with covid-19 using the ISARIC WHO Clinical Characterisation Protocol: prospective observational cohort study," BMJ, vol. 369, 2020.

[12] L. Yin, H. Mou, J. Shao, Y. Zhu, X. Pang, J. Yang, J. Zhang, . W. Shi, S. Yu and . H. Wangl, "Correlation between Heart fatty acid binding protein and severe COVID-19: A case-control study," PLOS ONE, vol. 16, no. 4, 2020.

[13] S. Lalmuanawmaa, J. Hussain and L. Chhakchhuak, "Applications of machine learning and artificial intelligence for Covid-19 (SARS-CoV-2) pandemic: A review," Chaos, Solitons and Fractals, vol. 139, 2020. 
medRxiv preprint doi: https://doi.org/10.1101/2020.08.02.20129767; this version posted August 10, 2020. The copyright holder for this preprint (which was not certified by peer review) is the author/funder, who has granted medRxiv a license to display the preprint in perpetuity.

It is made available under a CC-BY 4.0 International license.

[14] S. Uddin, A. Khan, M. E. Hossain and M. M. Ali, "Comparing different supervised machine learning algorithms for disease prediction," BMC Medical Informatics and Decision Making, vol. 19, no. 281, 2019.

[15] H. Baek, M. Cho, S. Kim, H. Hwang, M. Song and S. Yoo, "Analysis of length of hospital stay using electronic health records: A statistical and data mining approach," PLOS ONE:, vol. 13, no. 4, 2018.

[16] H. Chown, "A Comparison of Machine Learning Algorithms for the Prediction of Hepatitis C NS3 Protease Cleavage Sites," J Proteomics Bioinform, vol. 12, no. 5, pp. 088-093 , 2019.

[17] S. . L. Anwar, R. Ibrahim, N. Senan and M. Taujuddin, "Application of Data Mining Techniques for Medical Data Classification: A Review," MATEC Web of Conferences, vol. 150, 2018.

[18] R. Sujath, J. M. Chatterjee and A. . E. Hassanien, "A machine learning forecasting model for COVID-19 pandemic in India," Stochastic Environmental Research and Risk Assessment, vol. 34, p. 959-972, 2020.

[19] R. A. Fisher, "THE USE OF MULTIPLE MEASUREMENTS IN TAXONOMIC PROBLEMS," Annals of Eugenics, vol. 7, no. 2, pp. 179-188, 1936.

[20] R. C., Radhakrishna, "The Utilization of Multiple Measurements in Problems of Biological Classification," Journal of the Royal Statistical Society. Series B, vol. 10, no. 2, pp. 159-203, 1948.

[21] L. Breiman, "Random Forests," Machine learning, vol. 45, p. 5-32., 2001.

[22] N. Seliya, T. M. Khoshgoftaar and J. Van Hulse, "A Study on the Relationships of Classifier Performance Metrics," in 21st IEEE International Conference on Tools with Artificial Intelligence, 2009.

[23] T. Fawcett , "An introduction to ROC analysis," Pattern Recogn Lett, vol. 27, no. 8, pp. 861-874, 2006.

[24] W. Zhuo, S. J. John, L. Yang, L. Runyou, Z. Yuxin, C. Xiaoyu, Z. Lun, L. Qian, Z. Yu, Z. Jing, D. Ting, X. Xinyin, Z. Lijun., H. Jun, D. Yin, Z. Bo and W. Xianping, "Survival analysis of hospital length of stay of novel coronavirus (COVID-19) pneumonia patients in Sichuan, China," medRxiv, pp. 1-14, 2020.

[25] Q. Ruan, K. Yang, W. Wang, L. Jiang and J. Song, "Clinical predictors of mortality due to COVID-19 based on an analysis of data of 150 patients from Wuhan, China," Intensive Care Med, vol. 46, p. 846-848, 2020.

[26] D. D. Richman, R. J. Whitley and F. G. Hayden, Clinical virology, 4th edn., ASM Press: Washington:, 2016.. 
[27] World Health Organization., "Coronavirus Disease 2019 (COVID-19) Situation Report 46," World Health Organization., 2020.

[28] C. M. Bishop, Pattern Recognition and Machine Learning (Information Science and Statistics)., Heiddberg, Berlin.: Springer-Verlag, 2006.

[29] A. Ben-Hur, C. Ong , S. Sonnenburg and S. B. Schilkopf, "Support Vector Machines and Kernels for Computational Biology," Plose Computational Biololgy, vol. 4, 2008.

[30] E. Goel and E. Abhilasha, "Random forest: A review," Int J Adv Res Comput Sci softw Eng, vol. 7, pp. 251-257., 2017.

[31] Z. Zheng , F. Peng , B. Xu , J. Zhao and H. Liu, "risk factors of critical and mortal COVID-19 cases: A systematic literature review and meta-analysis," Journal of infection., 2020.

[32] P. Marik, P. Kory and J. Varon, "Does vitamin D status impact mortality from SARS-COV-2 infection?," Medicine in Drug Discovery, 2020.

[33] N. Zhu , D. Zhang and W. Wang , "A Novel Coronavirus from patients with pneumonia in china," The New England journal of medicine, vol. 382, no. 8, pp. 727-733, 2020.

[34] L. Li, Z. Yang, Z. Dang, C. Meng, J. Huang, H. Meng, D. Wang, G. Chen, J. Zhang, H. Peng and Y. Shao, "Propagation analysis and prediction of the COVID-19," Infectious Disease Modelling, vol. 5, pp. 282-292, 2020.

[35] X. L. F. L. G. Z. C. M. L. W. Zebin Zhao, "Prediction of the COVID-19 spread in African countries and implications for prevention and controls: A case study in South Africa, Egypt, Algeria, Nigeria, Senegal and Kenya," Science of the Total Environment, pp. 1-34, 2020.

[36] H.-T. Z. J. G. Y. X. M. W. Y. G. C. S. X. T. L. J. M. Z. X. H. Y. X. H. C. Y. C. T. R. F. W. Y. X. S. H. Li Yan, "An interpretable mortality prediction model for COVID-19 patients," nature machine intelligence, 2020.

[37] S. Y. X. Z. N. W. Q. P. D. L. A. L. Wen Zhao, "Clinical characteristics and durations of hospitalized patients with COVID-19 in Beijing: a retrospective cohort study," medRxiv, 2020.

[38] A. M. ,. P. G. ,. F. F. ,. A. R. V.-K. U. R. T. R. P. M. A. Sina F. Ardabili, "COVID-19 Outbreak Prediction with Machine Learning," 2020.

[39] H. M. J. S. Y. Z. X. P. J. Y. J. Z. W. S. S. Y. H. W. Li Yin, "Correlation between Heart fatty acid binding protein and severe COVID-19: A case-control study," PLOS ONE, vol. 15, no. 4, pp. 1-7, 2020. 
[40] G. James, D. Witten, . T. Hastie and R. Tibshirani , An Introduction to Statistical Learning, New York: Springer Science+Business Media, 2013.

[41] M. Mayo, . L. Chepulis and R. G. Paul, "Glycemic-aware metrics and oversampling techniques for predicting blood glucose levels using machine learning," PLOS ONE , vol. 14, no. 12, 2019.

[42] H. T. Abbas, . L. Alic, M. Erraguntl, . J. X. Jil , M. AbdulGhani, Q. H. Abbasi and M. . K. Qaraqe, "Predicting long-term type 2 diabetes with support vector machine using oral glucose tolerance test," PLoS ONE, vol. 14, no. 12, 2019.

[43] M. Ethan, G. David, G. Brian, P. K. and S. Joel, "Using machine learning and an ensemble of methods to predict kidney transplant survival," PLOS ONE, vol. 14, no. 1, 2019.

[44] A. Manal, A.-M. Mouaz, K. Steven, B. Clinton, E. Jonathan and S. Sherif, "Predicting diabetes mellitus using SMOTE and ensemble machine learning approach: The Henry Ford Exerclse Testing (FIT) project," PLOS ONE , vol. 12, no. 7, 2019.

[45] L. Yanhong, L. Zhi, G. Husheng, C. Hongyan, S. Chunying, G. Xingping and Z. Yanbo, "Predicting congenital heart defects: A comparison of three data mining methods," PLOS ONE, vol. 12, no. 5, 2017.

[46] Y. Liu, Y. Zhou, S. Wen and C. Tang, "A Strategy on Selecting Performance Metrics for Classifier Evaluation," International Journal of Mobile Computing and Multimedia Communications, vol. 6, no. 4, pp. 20-35, 2014.

[47] L. A. Jeni, J. F. Cohn and F. De La Torre, "Facing Imbalanced Data Recommendations for the Use of Performance Metrics," in Int Conf Affect Comput Intell Interact Workshops, 2013. 


\section{Distribution of age group and survival outcome}

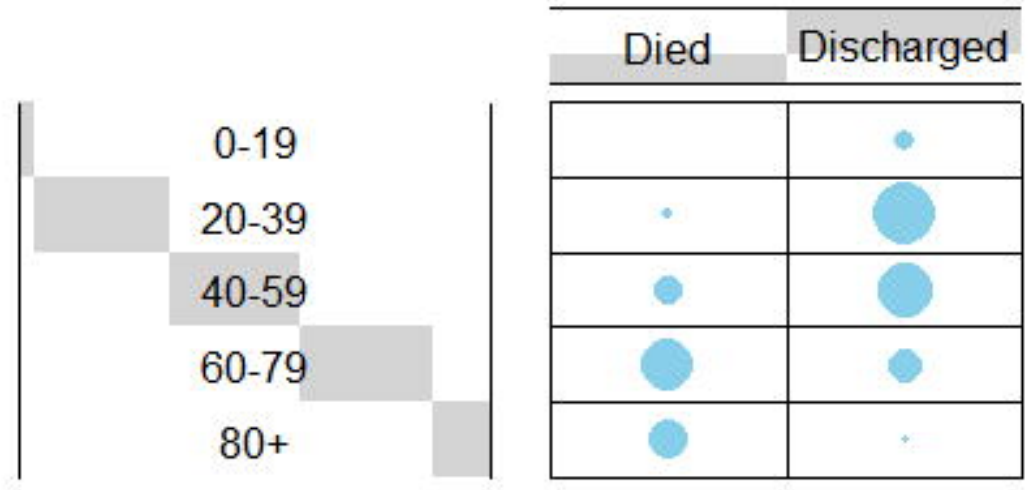




\section{symptoms vs outcome}

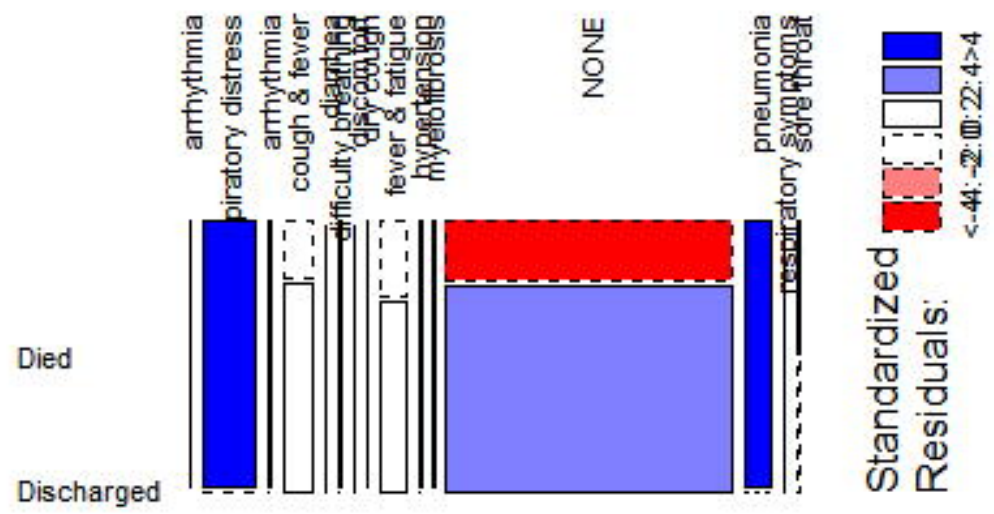



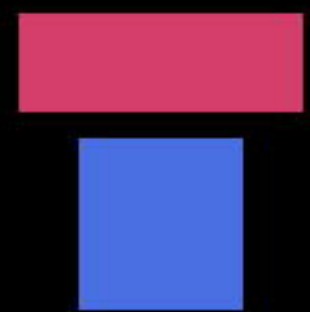
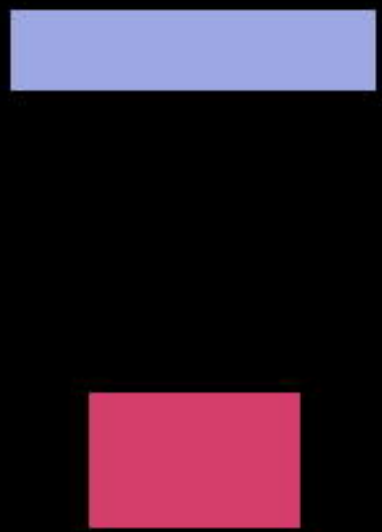

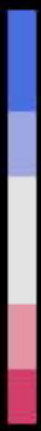




\section{LOS vs outcome}

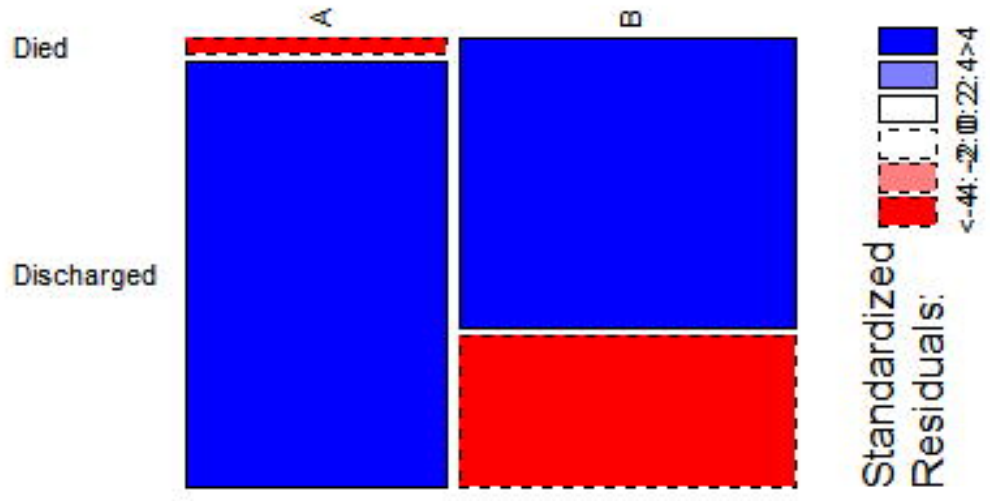




\section{Importance of $\mathrm{V}$ ariables}

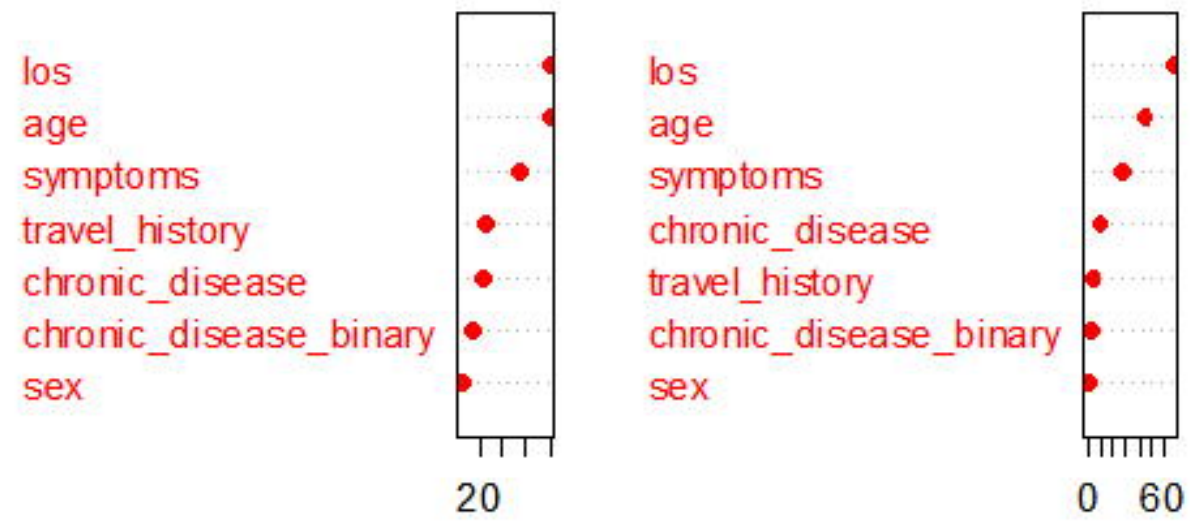

MeanDecreaseAc

MeanDecrease 